\title{
Poesia e linguagem na primeira recepção de Nietzsche dos escritos de August Wilhelm Schlegel
}

\author{
Anna Hartmann Cavalcanti*
}

Resumo: Em 1863, último ano de seus estudos na célebre escola Pforta, Nietzsche leu as Lições sobre belas-letras e arte e o ensaio Bürger, de A.W. Schlegel, tendo elaborado anotações sobre ambos os textos. A partir de tais leituras, teve acesso a uma detalhada exposição da teoria romântica, no que diz respeito às questões da arte e da linguagem, assim como a uma análise da obra do poeta Gottfried August Bürger. O interesse pela estética romântica de August Schlegel permaneceu vivo nos anos seguintes, estendendose a todo período de elaboração de $O$ Nascimento da tragédia. Neste artigo pretendo examinar a recepção de Nietzsche dos escritos de Schlegel, especialmente do ensaio Bürger, assim como elucidar aspectos importantes do diálogo que estabeleceu com o primeiro romantismo alemão.

Palavras-chave: Nietzsche-A.W. Schlegel - primeiro romantismo alemão - linguagem, poesia.

* Professora da Universidade Federal do Estado do Rio de Janeiro (Unirio), Rio de Janeiro, Brasil. Correio eletrônico: anna.hart.cav@gmail.com 
Cavalcanti, A. H.

\section{Introdução}

Nietzsche formou seu conhecimento da primeira estética romântica sobretudo a partir das teses apresentadas por A.W. Schlegel em suas Lições sobre belas-letras e arte, proferidas em Berlim em 1802, e do ensaio Bürger, ambos publicados em 1828. Schlegel pretendia, nas Lições sobre belas-letras e arte, expor os principais aspectos da primeira estética romântica, especialmente a tese sobre o caráter autônomo da arte. Seu objetivo era analisar o debate a partir do qual a nascente teoria estética se formou, assim como explicitar a crítica dessa teoria às concepções da estética clássica.

Em 1863, último ano de seus estudos em Pforta, Nietzsche leu, pela primeira vez, as Lições sobre belas-letras e arte e o ensaio Bürger, tendo elaborado anotações sobre ambos os textos (KGW I/3, p. 103-106). Na escola Pforta foi aluno de um dos mais significativos historiadores da escola romântica, August Koberstein, de quem provavelmente recebeu o incentivo para essas leituras. ${ }^{1}$ Em suas Lições, August Schlegel desenvolveu uma concepção dinâmica da natureza, caracterizando-a não como um conjunto de objetos do mundo exterior, mas como uma força ativa, produtora, um incessante movimento de criação. A natureza representa, segundo a concepção romântica, um singular modelo para o artista: este não procura a natureza fora de si, como um modelo externo, mas em si próprio, como um impulso a partir do qual ele cria. Nesse sentido, o artista não imita os objetos da natureza, mas imita a natureza na medida em que esta é um princípio produtor, procurando formar e criar como ela. ${ }^{2}$ Nietzsche não apenas transcreveu detalhadamente essa reflexão sobre a natureza como modelo artístico, mas anos depois retomou

1 Cf. BEHLER, E. Nietzsche und die Frühromantische Schule. Nietzsche-Studien 7, 1978, p. 70.

2 Cf. SCHLEGEL, A.W. Die Kunstlehre. Kritische Schriften. Lohner, E. (org). Stuttgart: W. Kohlhammer Verlag, v.2, 1963, p. 84-99.

122 | Cad. Nietzsche, Guarulhos/Porto Seguro, v.38, n.2, p. 121-148, maio/agosto, 2017. 
essa reflexão no fragmento 12(1) e em $O$ nascimento da tragédia. ${ }^{3}$ Tais anotações, elaboradas quando Nietzsche era estudante em Pforta, foram retomadas pelo então jovem professor da universidade da Basiléia e serviram de base para a reflexão desenvolvida ao longo do período de redação de $O$ nascimento da tragédia. Os escritos dessa época, como observaram Johann Figl e Hans-Gerald Hödl, são o resultado não apenas de leituras elaboradas no contexto dos estudos escolares, mas também das que surgiram da própria iniciativa do jovem Nietzsche, indicando os autores pelos quais se interessava e "a forma muito individual como os recebia" (KGW I/3, p.VI). O interesse que se forma pela estética romântica de August Schlegel, testemunhado por esses primeiros escritos, permanece vivo, como veremos, nos anos seguintes, estendendo-se a todo período de elaboração de $O$ Nascimento da tragédia.

No final do excerto das Lições sobre belas-letras e arte, acima mencionado, Nietzsche acrescentou anotações extraídas de sua leitura do ensaio Bürger (KGW I/3, p. 106). Nesse ensaio, produzido em 1800, Schlegel analisa aspectos da obra e da reflexão estética do poeta Gottfried August Bürger, autor do poema Lenore, de enorme sucesso na Alemanha no século XVIII, a quem atribui o mérito inestimável de reavivar, através de sua arte e de suas pesquisas, a poesia popular alemã. ${ }^{4} \mathrm{O}$ ensaio retoma uma série de aspectos da estética do primeiro romantismo alemão, a partir dos quais August Schlegel desenvolve sua interpretação da obra de Bürger. Nietzsche, por sua vez, retira do ensaio poucos, mas significativos trechos que não apenas relacionam-se uns aos outros, formando um campo bem delimitado de questões, mas também a determinadas passagens extraídas das Lições sobre belas-letras e arte, nas quais é tratado o tema

3 Sobre esse tema, ver CAVALCANTI, A. H. Nietzsche e a leitura de Do Belo Musical de Eduard Hanslick. In: Cadernos Nietzsche n. 16, São Paulo, 2004, p. 53-84.

4 SCHLEGEL, A.W. Bürger In: Kritische Schriften. Staiger, E. (org). Zürich und Stuttgart: Artemis Verlag, 1962, p. 127-190. Para as citações utilizarei o título do ensaio, seguido do número da página. 
da especificidade da forma de expressão poética. Em suas anotações, Nietzsche privilegia claramente um tema, a saber, o da linguagem e dos meios de expressão utilizados pelo poeta, particularmente o uso de alegorias nas antigas canções populares.

O objetivo deste artigo é analisar a leitura de Nietzsche do ensaio Bürger, realizada em 1863, a partir do confronto entre os trechos por ele extraidos e a rede temático-conceitual mais ampla que constitui as passagens nas quais os trechos estão inseridos. Trata-se, primeiramente, de analisar as passagens do ensaio de Schlegel das quais Nietzsche extraiu anotações, articulando-as com as Lições sobre belas letras e arte sempre que surgir uma configuração temática comum, a fim de evidenciar não apenas a trama conceitual mais ampla do ensaio, mas também o sentido que ela imprime aos trechos destacados por Nietzsche. Em seguida, pretendo elucidar a relação interna entre os trechos transcritos, delimitando o campo temático que daí emerge e estabelecendo conexões com os escritos do período de elaboração de $O$ nascimento da tragédia. Pretendo mostrar, a partir do exame dessas anotações, que o principal tema evocado por Nietzsche é o da especificidade da linguagem poética, tema este não apenas retomado, mas reiteradamente analisado ao longo do período de elaboração de sua primeira obra. ${ }^{\mathbf{5}}$

Ernst Behler, em seu artigo "Nietzsche und die Frühromantische Schule", coloca no centro de suas reflexões uma pertinente questão: ele indaga o que propriamente Nietzsche entendia sob o termo romantismo e em que medida o uso que fazia do termo compreendia o primeiro romantismo alemão, concebido como uma forma especial de romantismo que floresceu em torno da revista Athenaeum, no curto período que abrange os anos de 1795 a 1800. Behler argumenta que a critica de Nietzsche ao romantismo como forma de vida declinante,

5 Com exceção de algumas passagens de "Sócrates e a tragédia" e $O$ nascimento da tragédia, nas quais utilizei, respectivamente, as traduções de Marcos Sinésio Fernandes/Maria Cristina de Souza (MSF/MCS) e J. Guinsburg (JG), as demais traduções das citações de Nietzsche, assim como aquelas dos escritos de A.W. Schlegel, são de minha autoria.

124| Cad. Nietzsche, Guarulhos/Porto Seguro, v.38, n.2, p. 121-148, maio/agosto, 2017. 
que atravessa seus escritos sobretudo a partir de Humano demasiado humano, refere-se não às teses da primeira escola romântica, caracterizada por um movimento de reflexão infinita, pelo estilo fragmentário e pela estreita conexão entre arte e filosofia, mas sim ao que se denomina, em geral, romantismo tardio. Em seu artigo, Behler enfatiza a especificidade da visão filosófica de mundo do primeiro romantismo alemão, marcando sua diferença em relação aos aspectos do romantismo criticados por Nietzsche no último período de sua obra. ${ }^{6}$ As observações de Behler, aliadas ao debate acerca da periodização do romantismo ${ }^{7}$, nos convidam a delimitar logo de início, dentro desse vasto movimento, aquele que foi o objeto de interesse de Nietzsche em seus primeiros escritos.

Trata-se, portanto, de analisar as leituras de Nietzsche de um integrante da primeira escola romântica, August Wilhelm Schlegel, especialmente aqueles escritos, tais como Lições sobre belas letras e arte e o ensaio Bürger, nos quais se dedicou a expor as teses do primeiro romantismo ou delas partiu para construir sua interpretação. Pretendo mostrar como o exame das anotações produzidas em 1863 torna possível não apenas elucidar a recepção de Nietzsche dos escritos de August Schlegel, mas importantes aspectos de seu diálogo com o primeiro romantismo alemão.

$6 C f$. BEHLER, E. Nietzsche und die Frühromantische Schule. Nietzsche-Studien 7, 1978, p. 65-66.

7 Segundo Gusdorf, a dificuldade de se chegar a uma definição do romantismo alemão deve-se à enorme vitalidade desse movimento, cuja duração responde a diferentes configurações, o que implica, em cada uma das fases, o surgimento, o reforço ou atenuação de características específicas. Entre as inúmeras periodizações propostas para o movimento romântico alemão, cabe mencionar a que estabelece uma divisão em três momentos: a juventude do romantismo (Frïhromantik), seu período mais fecundo, que corresponde aos anos 1798 a 1802, em seguida o período da maturidade (Hochromantik), de 1802 a 1816, e enfim, o período tardio (Spätromantik), de 1816 a 1830, no qual o reordenamento das tradições culturais, pelo qual o romantismo imprime um novo sentido ao passado, é convertido em um conservadorismo nostálgico, de caráter tanto político quanto religioso. Cf. GUSDORF, G. Le savoir romantique. In: Le romantisme. Tome I. Paris: Payot, 2011, p. 95. 
Cavalcanti, A. H.

\section{Ensaio Bürger - primeiro e segundo trecho transcrito por Nietzsche}

Nos primeiros anos de sua vida universitária, por volta de 1786, o jovem Schlegel foi aluno de Gottfried August Bürger, professor de Estética na Universidade de Göttingen e já nessa época um renomado poeta, criador da célebre Lenore. Os laços tornaram-se cada vez mais estreitos até formar uma sólida amizade entre o poeta e o jovem filólogo. No ensaio Bürger, escrito após a morte do poeta, Schlegel desenvolve uma exposição detalhada de sua obra e, ao mesmo tempo, problematiza as duras críticas feitas por Schiller, em 1792, no Jenaischen Literatur-Zeitung, à criação poética de Bürger.

No centro das objeções de Schlegel encontra-se o entrançamento entre vida e obra elaborado por Schiller em sua crítica, da qual resulta uma consideração do poeta a partir do homem e na qual as circunstâncias da vida, especialmente a formação de Bürger, são evocadas como elementos para a avaliação estética. Schlegel observa que tal perspectiva coloca a interrogação sobre a poesia num domínio que lhe é estranho, já que mesmo que as particularidades de um homem se revelem de forma mais ou menos imediata em sua criação, a obra deve ser considerada como um produto da livre atividade e avaliada estritamente a partir do que foi realizado pelo poeta. Quando o crítico se atém à obra, ele pode vê-la historicamente, considerando os modelos evocados pelo poeta, considerando os gêneros poéticos da época, os objetos por ele escolhidos, que em parte foram herdados, assim como a forma da poesia e o modo pela a qual a linguagem foi elaborada. Na atividade crítica é necessário, portanto, segundo Schlegel, que a pessoa do autor seja separada da obra, a fim de orientar a avaliação sobretudo conforme o conteúdo e os princípios artísticos da obra.

Schlegel enfatiza, em sua objeção a Schiller, que não caberia ao crítico indagar se o poeta poderia expressar seu mundo interior

$126 \mid$ Cad. Nietzsche, Guarulhos/Porto Seguro, v.38, n.2, p. 121-148, maio/agosto, 2017. 
de outra maneira em sua obra, já que diferentemente do objeto, passível de ser examinado historicamente e segundo leis artísticas, o sujeito, a relação entre a pessoa do poeta e sua obra, permanece um domínio insondável, determinável "ao infinito". A respeito desse aspecto do processo de criação, pelo qual o domínio inconsciente é transposto para o domínio da linguagem poética, Schlegel observa: "entre o íntimo da alma e sua manifestação em uma obra de arte intervêm órgãos e meios que tornam ligeiramente incompleta a comunicação ou a desfiguram" (Bürger, p. 133). Aqui Schlegel refere-se ao processo de transposição entre o mundo interno e sua expressão na linguagem que havia sido descrito, em suas Lições sobre belas letras e arte, como um entrelaçamento entre "sensação e reflexão". ${ }^{8}$ Na experiência do artista, o processo de criação é orientado não somente por uma atividade inconsciente, mas também por um propósito, uma espécie de motivo que estimula a livre atividade, convertendo a sensação em objeto da reflexão consciente. Ainda que a atividade inconsciente desempenhe um importante papel, pois possibilita que o artista permaneça imerso em sua criação, um equilíbrio entre ambas é necessário, unindo em graus variados a atividade inconsciente e autoconsciente no processo artístico. A pressuposição de dois diferentes domínios, que estão em permanente interação, abordado nas Lições, é formulada em Bürger como uma distância entre o mais íntimo da alma e sua expressão na obra de arte, indicando que algo se perde ou é significativamente deslocado na passagem entre as duas esferas.

A imagem evocada por Schlegel, logo em seguida, para ilustrar essa defasagem entre o interior e sua expressão na linguagem corresponde ao primeiro trecho transcrito por Nietzsche: "Existem homens que não conseguem rir ou chorar sem fazer caretas repugnantes, mesmo quando o seu sentimento é o mais brando e

8 Cf. SCHLEGEL, A.W. Die Kunstlehre. Kritische Schriften. op.cit., p. 26. Ver também p. 30-31 e 7475. Nas próximas citações utilizarei a abreviatura Lições, seguida do número da página.

Cad. Nietzsche, Guarulhos/Porto Seguro, v.38, n.2, p. 121-148, maio/agosto, 2017. | 127 
Cavalcanti, A. H.

nobre" (KGW I/3, p. 106). O processo de transposição é ilustrado por essa imagem, que, por sua vez, é transcrita pelo jovem estudante com a observação de que se trata de "pensamentos" retirados do ensaio Bürger. Nietzsche transcreve literalmente o texto, mas introduz uma ligeira modificação, acrescentando o verbo "rir" ao lado do "chorar", ampliando, assim, a imagem de Schlegel, ao incluir nela a sensação de prazer. Esse pequeno trecho transcrito, que parece não fazer sentido algum quando lido no excerto de Nietzsche, adquire um significado cada vez mais preciso quando inserido no contexto mais amplo do ensaio de Schlegel. O tema por ele evocado está, como veremos mais adiante, em surpreendente proximidade com os demais trechos extraídos do ensaio, o que evidencia uma articulação, um núcleo comum que liga os pensamentos uns aos outros, configurando um campo bem delimitado de questões.

August Schlegel trata, em seguida, do conceito de popularidade que desempenha um importante papel ao longo da trajetória poética de Bürger. Em uma arte de caráter popular, que se dirigia a leitores de diferentes camadas sociais, mesmo as mais desfavorecidas, os princípios que deveriam caracterizar no mais alto grau o conteúdo da poesia eram "clareza e fácil compreensão" (Bürger, p.137). Para elucidar o termo "clareza" [Klarheit], assim como o papel que desempenha na poesia popular, é preciso distingui-lo do termo "precisão" [Deutlichkeit]: a clareza, na concepção de Bürger, se faz presente até mesmo nos casos em que o poeta necessita encobrir a ação, envolvê-la em uma espécie de véu, para produzir a impressão por ele buscada. Já a precisão, que corresponde à supremacia do entendimento na arte, requer que a poesia seja apreendida clara e racionalmente, nela introduzindo a exigência de inteligibilidade. Schlegel escreve a esse respeito: "Tudo compreender, ou seja, querer tudo apreender com o entendimento, é certamente uma aspiração bastante impopular" (Bürger, p. 138). O entendimento, descrito nas Lições (p. 81) como um "permanente formular de finitudes", apropria-

128 Cad. Nietzsche, Guarulhos/Porto Seguro, v.38, n.2, p. 121-148, maio/agosto, 2017. 
se dos signos linguísticos, imprime-lhes uma forma determinada, constituindo um horizonte estável que delimita nossa visão das coisas. A pura precisão, orientada pelas determinações do entendimento, uniformiza nossa visão das coisas, ao passo que a clareza, pelo uso que faz da expressão indireta e figurada, intensifica a percepção, despertando um jogo ilimitado de associações. Schlegel argumenta que tanto a Bíblia, compreendida em geral de "modo muito fragmentário", quanto as antigas canções de igreja, "impregnadas de ousadas alegorias" (Bürger, p.138), são altamente populares. Diferentemente das novas canções, monótonas e desprovidas de imagens, as antigas eram caracterizadas por um conteúdo impreciso assim como por uma ousada expressão alegórica. É justamente o simbolismo do modo de expressão que desperta vivamente a fantasia e possibilita uma forma de compreensão que nasce impulsionada pelas imagens. A clareza da forma, obtida por meio do uso de figuras e tropos, desencadeia um rico processo de ligação das imagens umas às outras, possibilitando um modo de compreensão que se dá por livre associação, o que é de imediato impossibilitado pela precisão da forma, na qual o material poético é decomposto em signos gerais. Dessa trama conceitual emerge o segundo trecho transcrito, de forma literal, por Nietzsche: "Nossa existência repousa sobre o inapreensível e a poesia, que surge dessas profundezas, não pode querer simplesmente decompôlo" (KGW I/3, p. 106).

Nessa passagem, Schlegel diferencia duas formas de linguagem que foram denominadas, em suas Lições (p. 81), como a linguagem do "signo conceitual" e a linguagem do "símbolo". Como a linguagem comum é formada por um conjunto de signos conceituais, gerais e arbitrários, não lhe é possível apreender tudo que é pensado em uma única e individual representação de um objeto. Schlegel, que associa aqui a representação individual com o conceito de Kant de "ideia estética" (Lições, p. 77), refere-se a uma representação que dá muito o que pensar, sem que, contudo, seja possível encontrar na linguagem 
meios para expressá-la. Essa impossibilidade de nomear é transposta pela poesia por meio de uma linguagem simbólica, que desempenha, assim, um papel fundamental como forma de expressão: por meio dela o poeta pode explorar a amplitude semântica das palavras, deixando flutuar em torno delas a pluralidade de sentidos, através da qual o inapreensível, do qual nasce a poesia, não é decomposto, como nos signos conceituais, mas comunicado em sua riqueza.

Percebe-se, assim, uma significativa articulação entre o primeiro e o segundo trecho transcrito por Nietzsche. Enquanto no primeiro é tratada a distância entre o mundo interior e sua manifestação na obra de arte, pelo qual é indicado o caráter impreciso e fragmentário do modo de expressão poético, no segundo, através do termo "inapreensível", que abarca o domínio mais profundo da experiência interna, é indicada a especificidade da forma de expressão que caracteriza a poesia e a diferencia dos signos conceituais.

Na parte seguinte do ensaio, que se situa no campo temático do último trecho anotado por Nietzsche, a criação poética de Bürger é analisada no horizonte mais amplo das antigas canções populares. Schlegel elabora, primeiramente, uma breve reflexão sobre a gênese e a especificidade das antigas canções populares, os chamados "romanzen". O termo "romance", utilizado com esse significado, pela primeira vez, na Espanha, designava a "língua vulgar", a "língua do povo", a partir da qual se constituíram narrativas caracterizadas por concisão e simplicidade, que se diferenciaram, aos poucos, dos mais extensos "romances", originariamente livros de cavaleiros (Bürger, p.140). As antigas canções, escreve Schlegel, não foram criadas "intencionalmente para o povo", mas nasceram "em meio ao povo", o que é evidenciado por sua forma simples e concisa de expressão, cujo conteúdo se mantinha em estreita afinidade com os modos de pensar e de sentir de cada povo, penetrava facilmente e se inscrevia profundamente na memória. Nas antigas poesias populares, nas quais a ação era tecida com a mais pura intuição, o enredo 
desdobrava-se por si mesmo, "sem intenção ou consciência" (Bürger, p.142), tornando desnecessário qualquer minúcia na descrição do objeto. Os motivos mais íntimos da ação, que nas obras dos grandes mestres são intencionalmente elaborados, fluem nos antigos poemas instintivamente, eles surgem como que por acaso, enquanto o sentido do todo é introduzido já nas primeiras estrofes por meio de uma primorosa técnica artística.

Em sua análise das antigas canções, Schlegel ressalta o caráter orgânico da obra de arte, descrito como um "movimento em direção ao todo, à disposição, construção articulada e proporção, no qual o particular existe apenas por intermédio do todo" (Bürger, p. 176). Esse tema é retomado nas Lições (p. 91), nas quais a criação é descrita como uma atividade orgânica, "organizada e organizadora", em permanente movimento de expansão e retorno a si própria. ${ }^{9}$

A caracterização da antiga poesia popular é construída em contraposição à poesia moderna, à tendência de introduzir detalhes e um excesso de explicações que sobrecarregam a narrativa. No centro da oposição entre a arte antiga e moderna encontram-se os conceitos de "simplicidade" e "descrição". Enquanto a antiga poesia, com sua simplicidade e engenhosa concisão, era capaz de transportar o ouvinte, despertando vivamente sua fantasia, a poesia moderna, sobrecarregada com descrições e artifícios retóricos, introduz na arte uma espécie de "exatidão aritmética" (Bürger, p. 148) que aniquila não apenas o seu poder de encantar, mas também toda a surpresa da narrativa. August Schlegel problematiza aqui aspectos da estética da Aufklärung, como a ênfase na inteligibilidade, que tende a suprimir aquilo que constitui fundamentalmente a arte, a transformação da aparência em "aparência lúdica" (Lições, p. 78), o jogo no qual ela envolve o ouvinte, no qual predominam não as leis do entendimento, mas os da imaginação criadora.

9 Nietzsche, em sua leitura das Lições, anota toda a passagem na qual Schlegel analisa o caráter orgânico da obra de arte. $C f$. KGW I/3, p. 104.

Cad. Nietzsche, Guarulhos/Porto Seguro, v.38, n.2, p. 121-148, maio/agosto, 2017. | 131 
As distinções entre "instinto" e "intenção", "simplicidade" e "descrição", acima analisadas, nos levam a um tema reiteradamente abordado por Nietzsche ao longo de todo o período de elaboração de sua primeira obra. Nos fragmentos póstumos de 1869 encontram-se inúmeras indicações de uma cuidadosa leitura das Lições sobre arte dramática e literatura, de August Schlegel, nas quais são analisados aspectos das antigas e modernas tragédias. ${ }^{10}$ Essas anotações de leitura são retomadas e aprofundadas nas conferências apresentadas na Basiléia no início de 1870. Em "O drama musical grego", Nietzsche faz uma contraposição entre a tragédia moderna, elaborada a partir de "uma teoria abstrata", de uma "imitação direta dos antigos", e o antigo drama, como "arte que cresce da noite profunda", que "brota inconscientemente da vida do povo" (GMD/DM, KSA 1.516). Trata-se de enfatizar a diferença entre a formação gradual e espontânea da tragédia ao surgimento artificial do teatro moderno, que resulta de uma imitação consciente da arte antiga, apoiada em um saber teórico. Esse desenvolvimento artificial da arte, orientado intencionalmente segundo um modelo, marca uma ruptura com as tradições populares que enraizavam a arte na experiência viva da cultura. Na mesma conferência, Nietzsche comenta a concepção de August Schlegel do coro como espectador ideal, assim como ressalta a simplicidade das antigas tragédias, observando que "nada há nelas que se precise calcular", falta aí toda intriga, toda combinação artificial, constitutiva da tragédia moderna, e até mesmo a "astúcia de alguns heróis do mito conserva algo dessa simplicidade" (GMD/DM, KSA 1.526). Aqui é evocada não apenas a interpretação do coro, desenvolvida por Schlegel, mas também a estrutura simples da arte antiga, enraizada

10 Luca Crescenzi desenvolveu uma detalhada análise da série de fragmentos póstumos, do outono de 1869, composta de anotações de Nietzsche sobre suas leituras das Lições sobre arte dramática e literatura. Grande parte das anotações, que trata da arte dramática antiga e, especialmente, do papel de Eurípedes no declínio da tragédia, serviu de base para a elaboração das conferências de 1870. Cf. CRESCENZI, L. Nietzsche, August Wilhelm Schlegel und die Spuren Lessings In: Nietzsche Studien 23, 1993, p. 385-392.

132 | Cad. Nietzsche, Guarulhos/Porto Seguro, v.38, n.2, p. 121-148, maio/agosto, 2017. 
num momento da cultura grega na qual não se constituíra um conceito e uma teoria, uma reflexão consciente sobre a arte.

Esse campo de interesses que se forma em torno das leituras de Schlegel torna-se ainda mais evidente na conferência "Sócrates e a tragédia", na qual Nietzsche utiliza uma estrutura argumentativa semelhante à acima exposta, com o intuito de marcar a diferença entre a "estética consciente" de Eurípedes e a antiga tragédia de Ésquilo e Sófocles. ${ }^{11}$ A esse respeito observa:

Eurípedes procura intencionalmente o que há de mais compreensível; seus heróis são realmente como eles falam. Mas também eles se expressam inteiramente, enquanto os personagens de Ésquilo e Sófocles são muito mais profundos e plenos que suas palavras: propriamente eles só balbuciam sobre si. Eurípedes cria as figuras enquanto, ao mesmo tempo, as disseca; diante de sua anatomia não existe nada mais oculto nelas. (ST/ST, KSA 1.539 , trad. MSF/MCS)

Diferentemente de Eurípedes, que introduz na tragédia o prólogo e constrói uma sólida rede de motivos que confere inteligibilidade a seus personagens, uma espécie de penumbra, que não chega a ser traduzida em palavras, envolve os personagens de Ésquilo e Sófocles. Eurípedes cria suas figuras ao mesmo tempo em que as disseca, de modo que nada mais fica oculto, ao passo que Ésquilo não constituíra ainda uma reflexão consciente sobre sua arte, predominando em suas tragédias as grandes cenas carregadas de pathos, uma linguagem rica de imagens e ritmos, a partir das quais o conteúdo que jamais chegava com clareza à consciência podia ganhar expressão. Nietzsche

11 Albert Henrichs mostrou, a partir de minuciosa análise, o papel decisivo da leitura de Nietzsche das Lições sobre arte dramática e literatura para a construção da imagem de Eurípedes em seus primeiros escritos. Enquanto no curso "Introdução à leitura de Sófocles", de 1870, Nietzsche cita diversas vezes as Lições de A.W. Schlegel, como observa Henrichs, em "Sócrates e a tragédia" e $O$ nascimento da tragédia, embora não se encontrem citações, inúmeras passagens nos remetem diretamente às teses de Schlegel. $C f$. HENRICHS, A. The last of the detractors: Friedrich Nietzsche's condemnation of Euripides. Greek, Roman and Byzantine Studies 27, 1986, p. 369-397. Ver também a respeito BEHLER, E. Sokrates und die Griechische Tragödie. Nietzsche und die Brüder Schlegel über den Ursprung der Moderne. In: Nietzsche-Studien 18,1989, p. 141-155. 
Cavalcanti, A. H.

desenvolve aqui um contraste entre uma arte excessivamente lançada à luz, intencionalmente elaborada e esmiuçada em seus detalhes, e uma arte cuja beleza repousava no conjunto, não na clareza do discurso, e cuja maestria consistia em fornecer ao espectador já "nas primeiras cenas, como que por acaso, todas as pistas necessárias à compreensão" (ST/ST, KSA 7.538). Ao contrário de um excesso de descrições e ornamentos, a maestria artística dos antigos trágicos consistia em "mascarar o necessário" (ST/ST, KSA 7.539), produzindo um efeito de conjunto no qual o todo predomina sobre a parte, o que nos remete a um modo de criação orgânico e instintivo.

Ainda que não haja nessa época evidências de uma releitura do ensaio Bürger, existem razões para supor que a leitura dos escritos de Schlegel sobre o teatro antigo, amplamente documentada nos fragmentos póstumos do período, tenha dado a Nietzsche a oportunidade de retomar pontos que ele havia destacado em suas leituras anteriores. Temas significativos, tais como o papel do instinto na criação poética e o caráter orgânico da obra de arte, não apenas abordados por Schlegel em seu ensaio Bürger, mas introduzidos como fio condutor de sua interpretação, encontram-se nas conferências de 1870 e contribuem para delimitar as fronteiras que separam a tragédia de Eurípides daquela de Ésquilo e Sófocles, bem como a tragédia antiga e moderna.

\section{Ensaio Bürger - terceiro trecho transcrito por Nietzsche}

No parágrafo seguinte, Schlegel inicia seu comentário a respeito do que considera uma verdadeira obra prima em matéria de poesia, uma "joia” esculpida por Bürger, que faz renascer o autêntico espírito das mais antigas canções populares: trata-se de Lenore, canção popular de enorme sucesso na Alemanha do final do século XVIII. Sobre o nascimento do poema, Schlegel faz uma interessante observação,

134 | Cad. Nietzsche, Guarulhos/Porto Seguro, v.38, n.2, p. 121-148, maio/agosto, 2017. 
que lhe teria sido transmitida pelo próprio Bürger, de que Lenore, diferentemente de outros poemas do autor, não teria nascido de imagens suscitadas por antigas poesias, mas de um "som perdido de uma antiga canção popular" (Bürger, p.156). Cabe lembrar que Nietzsche, durante o período de estudos em Pforta, não apenas compôs inúmeras canções, mas se ocupou intensamente com questões de estética musical, tendo elaborado, em 1864, um trabalho escolar sobre o primeiro canto coral de Édipo Rei que antecipa importantes elementos, desenvolvidos em sua primeira obra, sobre o papel do coro na tragédia antiga. ${ }^{12}$ No campo temático no qual se move o jovem estudante, a observação de Schlegel torna-se significativa, já que uma canção tão conhecida como Lenore não teria nascido do modelo de antigas poesias, mas sim da melodia de uma antiga canção, de um estado musical.

Em sua análise de Lenore, Schlegel ressalta a primorosa construção poética de Bürger, orientada segundo os princípios da mais autêntica poesia popular, entre os quais se destacam, como vimos, a concisão e simplicidade. Na narrativa, disposta de forma simples, sem excesso de descrições ou ornamentos, nada é demais. Ela se desdobra em três grandes planos, animados por vivas imagens, as quais, já no início, por meio de uma constante contraposição, de um lado as tropas que voltam alegremente para casa, de outro, a violenta paixão de Lenore, deixam pressentir o trágico desfecho. Através do contraste das imagens, o conjunto da trama é de imediato apresentado ao ouvinte, de modo que os motivos da ação vêm luz, pouco a pouco, num momento ou no outro, como que "por acaso". A concisão da forma de expressão e a economia nas descrições constituíam, como vimos, um traço importante das antigas canções, pois possibilitavam não apenas introduzir agilmente os motivos da

12 Bárbara Reibnitz mostrou que a concepção da tragédia "como obra de arte musical", assim como importantes elementos da reflexão desenvolvida em $O$ nascimento da tragédia, já se encontram delineados no texto de 1864. Cf. REIBNITZ, B. Ein Kommentar zu Friedrich Nietzsche „Die Geburt der Tragödie aus dem Geist der Musik“, Stuttgart/Weimar: J. B. Metzler, 1992, p.11. 
ação, como também captar o ouvinte, por meio da vivacidade das imagens, levando-o a uma ativa participação na narrativa. O elemento instintivo na elaboração das antigas poesias, ressaltado tanto por Schlegel em seu ensaio quanto por Nietzsche nas conferências do início dos anos 70, torna-se aqui especialmente visível, já que o poeta, inteiramente mergulhado em sua criação, não tinha intenção de explicar as imagens que se desdobravam em sua fantasia, o que pressuporia uma atitude de distanciamento, mas se concentrava em traduzir de forma viva a trama que aí se configurava. Schlegel observa a esse respeito: "Toda exposição verdadeiramente entusiasmada se perde em seu objeto" (Bürger, p.165). O perder-se seja na fantasia criadora, seja na história narrada constitui um traço essencial da experiência poética, que vale tanto para o poeta quanto para o ouvinte.

Schlegel observa, ainda, a respeito de Lenore, que um importante recurso artístico nela utilizado consiste em reter sempre algo, manter algo oculto na narrativa, de modo a intensificar o efeito poético e potencializar a impressão produzida. Desse parágrafo é extraído o último trecho anotado por Nietzsche:

É uma experiência conhecida que, para afugentar um fantasma, é preciso enfrentá-lo diretamente: o medo de aparições noturnas do mundo dos espíritos, tão profundamente enraizado na natureza humana, refere-se, com efeito, ao desconhecido e é, antes, suscitado por um sinistro pressentimento e pela incerteza de uma expectativa do que pela evidência de um presente assustador; e com este o poeta só pode desferir os maiores golpes, quando pouco a pouco já se apoderou dos estados de ânimo (KGW, I/ 3, p. 106).

Assim como o medo de aparições noturnas refere-se muito mais ao desconhecido do que a um presente assustador, assim também a arte poética deve cobrir a ação com uma espécie de véu, deixá-la como que no escuro, com o intuito de cativar e envolver o ânimo do ouvinte, transportando-o para o mundo criado pela arte. Schlegel relata um episódio que lhe foi narrado por Bürger muito esclarecedor a esse respeito. Ao ler o poema Lenore pela 
primeira vez a um amigo, Bürger quis lhe preparar uma surpresa. Enquanto lia, mantinha, como que distraidamente, um chicote em sua mão e ao ler a passagem sobre a varinha que magicamente abre o portão ${ }^{13}$, bateu com o chicote em uma porta que estava próxima. $\mathrm{O}$ amigo, já muito comovido pelo poema, saltou espantado, como se a coisa narrada realmente acontecesse diante de seus olhos. Aqui é tematizada a particularidade do mundo criado pela arte, cujo fim é a produção do jogo, da magia, que transporta o espectador para uma situação como se ele próprio a estivesse vivendo. Os meios artísticos através dos quais o artista se apodera do estado de ânimo dos ouvintes corresponde à capacidade de tornar uma narrativa tão viva que a "coisa descrita parece realmente estar diante de nossos olhos" (Bürger, p.158). A particularidade da arte consiste em fazer esquecer momentaneamente o mundo conhecido, composto por formas determinadas, a fim de tornar possível a participação em um mundo fictício, o mundo transfigurado da arte, no qual as coisas aparecem sob relações novas. Nesse mundo construído a partir de leis artísticas basta, como observa Schlegel em suas Lições, que algo pareça verdadeiro, que através da fantasia a disposição e a relação determinada das coisas na realidade possa ser transformada e vivenciada de novas perspectivas. ${ }^{14}$ A partir da imagem das aparições noturnas, Schlegel destaca um importante aspecto da arte, o de tornar possível, através da magia da representação, a participação em um mundo fictício, mas nem por isso menos vivo e significativo.

13 Trata-se da seguinte passagem: "A um portão de férreas grades /A rédea solta chegaram / E ao toque de uma varinha / Ferrolho e chave soltaram". Cf. Bürger, G. A. Leonor. In: COLEN, E. e DRUMOND, L. Das tempestades: a poesia alemã do Sturm und Drang, Belo Horizonte: FALE/UFMG, 2010, p.33.

14 Em sua leitura das Lições, Nietzsche destaca essa passagem, na qual Schlegel faz um jogo entre o termo "wahrscheinlichkeit" [verossimilhança] e "wahr scheinen" [parecer verdadeiro]. Cf. KGW I/3, p. 103. Ver também CAVALCANTI, A. H. Nietzsche leitor de August Schlegel. In: PASCHOAL, E. e FREZZATTI, W. 120 anos de Para a Genealogia da Moral. Ijuí: Editora Ijuí, 2008, p. 47-68, aqui p. 53.

Cad. Nietzsche, Guarulhos/Porto Seguro, v.38, n.2, p. 121-148, maio/agosto, 2017. $\mid \mathbf{1 3 7}$ 
Cavalcanti, A. H.

\section{A leitura de Nietzsche}

$\mathrm{O}$ interesse de Nietzsche por essa passagem do ensaio concentra-se na relação estabelecida, por meio da imagem, entre o temor do desconhecido, profundamente enraizado na natureza humana, e o recurso artístico do encobrimento, pelo qual o artista impele o ouvinte a participar vivamente da ação dramática. Nietzsche, curiosamente, transcreve a passagem do texto na qual Schlegel não mais comenta diretamente o poema de Bürger, tema de todo o parágrafo, mas emprega uma metáfora para esclarecer a produção do efeito estético na arte. Esse tema da participação na obra de arte já havia sido tratado na passagem do ensaio que corresponde ao segundo trecho transcrito por Nietzsche, no qual se buscava determinar a especificidade da literatura popular. Nela Schlegel havia mostrado como a Bíblia, "muito fragmentariamente compreendida', e as antigas canções de igreja, impregnadas de "ousadas alegorias", são altamente populares. As narrativas impregnadas de imagens e alegorias, cuja particularidade é manter algo encoberto, como que apenas sugerido, expressam uma vigorosa capacidade de comunicação e tal capacidade repousa no modo como é traduzido em imagens o "inapreensível". Na medida em que a poesia, nascida das "profundezas" (Bürger, p.138), não procura decompor sua experiência em signos gerais, mas expressá-la em uma linguagem de imagens, ela alcança uma capacidade intensificada de comunicação. Enfim, também a passagem do ensaio que corresponde ao primeiro trecho transcrito por Nietzsche encontra-se em estreita relação com essa temática. Aí a atividade expressiva é concebida como um processo de transposição, no qual intervém "órgãos e meios" que tornam imprecisa a comunicação, algo permanece oculto, formando-se uma lacuna entre a experiência interna e sua expressão, o que é ilustrado por Schlegel pela imagem dos "mais nobres sentimentos" que só podem ser exteriorizados por meio de uma tensão da expressão facial. Constata-se, assim, uma

138 Cad. Nietzsche, Guarulhos/Porto Seguro, v.38, n.2, p. 121-148, maio/agosto, 2017. 
articulação temática entre os trechos transcritos por Nietzsche, o que evidencia não apenas uma leitura cuidadosa, mas também um campo bem delimitado de interesse. Vejamos agora, reunidos num único texto, os trechos extraídos por Nietzsche:

Bürger. 1800. Pensamentos daí [extraídos]: Existem homens que não conseguem rir ou chorar sem fazer caretas repugnantes, mesmo quando o seu sentimento é o mais brando e nobre.

Nossa existência repousa sobre o inapreensível e a poesia, que nasce de tais profundezas, não pode simplesmente querer decompô-lo.

É uma experiência conhecida que, para afugentar um fantasma, é preciso enfrentá-lo diretamente: o medo de aparições noturnas do mundo dos espíritos, tão profundamente enraizado na natureza humana, refere-se, com efeito, ao desconhecido e é, antes, suscitado por um sinistro pressentimento e pela incerteza de uma expectativa do que pela evidência de um presente assustador; e com este o poeta só pode desferir os maiores golpes, quando pouco a pouco já se apoderou dos estados de ânimo (KGW I/3, p. 106).

As três transcrições são caracterizadas, de um lado, por uma alusão à experiência interna - "os mais nobres sentimentos", "as profundezas", "o medo" - de outro, pela descrição do modo como o mundo interno ganha expressão - as "caretas", "a poesia", o poeta que "se apodera dos ânimos". Tudo indica que o interesse do jovem Nietzsche se concentra no campo de relações que se abre entre um domínio inapreensível da experiência e sua forma de expressão poética, por meio da qual algo do desconhecido é, ao mesmo tempo, expresso e oculto, o que por sua vez se constitui como um recurso artístico que impele o ouvinte à viva participação na arte. A consideração, presente sob diversas perspectivas no excerto de Nietzsche, de uma ligação entre nossa experiência e um domínio mais profundo, que só pode ganhar expressão por meio da linguagem figurada da poesia, aponta para um importante tema desenvolvido no capítulo 5 de $\mathrm{O}$ nascimento da tragédia, no qual é tratado o processo de criação do poeta lírico. 
Nesse capítulo, Nietzsche desenvolve uma crítica à interpretação moderna da lírica grega, na qual Arquíloco é caracterizado como o primeiro artista subjetivo, o artista que diz eu e expressa, na poesia, toda a gama de suas paixões e desejos. Trata-se de colocar em questão, a partir dos pressupostos da metafísica da arte, a teoria moderna do poeta lírico, enfatizando o caráter não-artístico de todas as formas de expressão da vontade individual na arte. Vejamos, de forma concisa, a interpretação do processo de criação de Arquíloco. O poeta lírico se identifica, enquanto artista dionisíaco, à dor e à contradição do Uno Primordial e engendra uma réplica desse Uno Primordial como música. Ao reflexo musical da dor originária segue-se um segundo reflexo, correspondente à libertação da dor na aparência, pelo qual a música, sob efeito do sonho apolíneo, torna-se visível como "uma imagem de sonho alegórico" (GT/NT 5, KSA 1.44). É a partir da música e da poesia, entendidas como momentos distintos, que o poeta procura dar expressão a seu estado dionisíaco, um estado no qual não é o eu do poeta que cria, mas "o artista originário do mundo":

Quando Arquíloco, o primeiro lírico dos gregos, manifesta o seu amor furioso e, ao mesmo tempo, o seu desprezo pelas filhas de Licambes, não é a sua paixão que dança diante de nós em torvelinho orgiástico: vemos Dioniso e as Mênades, vemos o embriagado entusiasta Arquíloco imerso em sono profundo em alto prado alpestre, ..., e então Apolo se aproxima dele e o toca com seu laurel. $\mathrm{O}$ encantamento dionisíaco-musical do dormente lança agora a sua volta como que centelhas de imagens, poemas líricos, que em seu mais elevado desdobramento se chamam tragédias e ditirambos dramáticos (GT/NT 5, KSA 1.44, trad. JG).

Na poesia lírica e na tragédia, enquanto arte apolíneo-dionisíaca, o que se expressa não é a subjetividade do artista, mas tudo o que é sentido e conhecido no estado dionisíaco. As imagens poéticas, nascidas da música, são uma objetivação apolínea, uma alegoria do estado dionisíaco. O ponto de partida do processo de criação é a embriaguez dionisíaca do poeta, uma espécie de transbordamento

$140 \mid$ Cad. Nietzsche, Guarulhos/Porto Seguro, v.38, n.2, p. 121-148, maio/agosto, 2017. 
Poesia e linguagem na primeira recepção de Nietzsche ...

que não pode ser contido numa imagem, já que, enquanto forma, a imagem delimita, estabelece fronteiras. Tal experiência é, num primeiro momento, transposta musicalmente e, em seguida, traduzida poeticamente, em um mundo de imagens.

A relação entre música e linguagem, pressuposta no processo de criação do lírico, é retomada e analisada no capítulo 6 da mesma obra: "A melodia é, portanto, o que há de primeiro e mais universal, podendo por isso suportar múltiplas objetivações, em múltiplos textos" (GT/NT 6, KSA1.48, trad. JG). Diferentemente da palavra, particular e delimitada, o traço constitutivo da música é a generalidade e a indeterminação, o poder de fazer emergir de um único movimento sonoro múltiplas imagens e múltiplos textos. Uma sinfonia de Beethoven, como observa Nietzsche, suscita em cada ouvinte diferentes mundos de imagens, os quais comparados produziriam um resultado heterogêneo e, até mesmo, contraditório. O mesmo acontece nos casos em que o músico atribui título a uma sinfonia, esse título não busca expressar o conteúdo da música, ou indicar os objetos por ela imitados, mas constitui, antes, uma imagem figurada, uma alegoria que "não tem qualquer valor exclusivo em face de outras imagens" (GT/NT 6, KSA 1.50). A análise do processo de criação supõe, portanto, uma espécie de lacuna, de distância entre a imagem e o movimento sonoro que ela procura expressar, de modo que a relação que se forma entre as duas esferas não é uma relação de correspondência, mas uma relação simbólica. Nietzsche utiliza os termos símbolo [Symbol] e alegoria [Gleichnis], ambos indicativos de um modo figurativo de expressão, para caracterizar a relação da imagem poética com a indeterminação do elemento sonoro, observando que o artista procura uma expressão análoga à música e, por isso, sofre o seu poder, o que se traduz nas imagens turbulentas e irregulares da lírica.

É interessante destacar as imagens empregadas por Nietzsche para descrever a criação poética: o lírico "sente brotar um mundo Cad. Nietzsche, Guarulhos/Porto Seguro, v.38, n.2, p. 121-148, maio/agosto, 2017. | 141 
de imagens" do estado dionisíaco (GT/NT 5, KSA1.44) ou "é impulsionado a falar da música em alegorias apolíneas" (GT/NT 6, KSA1.51). O poeta luta para interpretar em imagens a música, mas como não é possível contê-la numa forma, precisa recorrer a uma linguagem impregnada de símbolos, que jamais chega a expressar com precisão tudo o que é experimentado na música. Nesse sentido, a palavra é sempre superficial e circunscrita, em relação ao que na melodia é profundo e ilimitado. Nietzsche enfatiza, desse modo, o limite da alegoria e do símbolo enquanto formas de expressão da linguagem. Mas esse limite constitui, paradoxalmente, a riqueza do modo figurativo de expressão. Em uma reflexão sobre a poesia no drama musical wagneriano, Nietzsche descreve a relação produtiva que se estabelece entre música e imagem: “A ação poética em Wagner possui muita grandeza. A palavra não age por sua extensão, mas por sua intensidade. A linguagem é pensada em um estado originário a partir da música. Daí a concisão e o caráter concentrado da expressão" (Nachlass/FP 1871, 9[72], KSA 7.301). Aqui a música é associada a um modo conciso e figurativo de expressão, característico da linguagem em sua origem. A poesia utiliza não a palavra em sua extensão, enquanto signo linguístico determinado e articulado à esfera comunicativa, mas a palavra concisa e aparentada à imagem, aproximando-se assim de um estado original onde a linguagem estava ligada a uma dimensão intensiva da experiência. A especificidade do modo de expressão figurativo é o de colocar a palavra a serviço da imagem, intensificando o poder significativo da linguagem. A forma simbólica e alegórica representa essa união entre a palavra e a imagem, a partir da qual é possível dar expressão àquele domínio da experiência que escapa às determinações linguístico-conceituais. ${ }^{\mathbf{1 5}}$

15 Para uma análise aprofundada da relação entre música e palavra ver CAVALCANTI, A. H. Símbolo e Alegoria: a gênese da concepção de linguagem em Nietzsche. São Paulo: Annablume/Fapesp, Rio de Janeiro: DAAD, 2005, p. 205-213.

142 | Cad. Nietzsche, Guarulhos/Porto Seguro, v.38, n.2, p. 121-148, maio/agosto, 2017. 
O ensaio de Schlegel tem como tema a obra e o processo de criação de um poeta popular, Bürger, ao passo que Nietzsche tematiza nos capítulos 5 e 6 de sua primeira obra o processo de criação do "primeiro lírico grego", Arquíloco, que introduziu a canção popular na literatura. Enquanto Schlegel interpreta os laços que unem a obra de Bürger às mais antigas canções populares, Nietzsche argumenta que a lírica de Arquíloco introduz na antiga literatura grega ritmos e motivos das canções populares - as canções de culto a Dioniso, as canções entoadas na colheita da vinha - produzindo uma profunda inovação da forma métrica e do material linguístico da poesia. ${ }^{16}$ Porém, em sua interpretação da criação poética dos líricos, Nietzsche não mobiliza apenas fontes históricas e o modo como foram recebidas pela filologia clássica, mas constrói um intenso diálogo com a metafísica da música de Schopenhauer e com os comentários de Schiller sobre o processo de criação, ambos citados nos capítulos acima mencionados. Referências diretas a August Schlegel são introduzidas apenas nos capítulos 7 e 8 de $O$ nascimento da tragédia, nos quais é analisado o papel do coro na tragédia antiga. É possível, no entanto, constatar que se delineia ao longo da reflexão de Nietzsche uma estrutura, como que um arcabouço, semelhante àquela que compõe os trechos extraídos do ensaio de Schlegel: enquanto o excerto nos remete a uma espécie de lacuna entre o que é vivido e o que é comunicado, a um domínio inapreensível da experiência interna que só chega a ser traduzido de modo significativo pela imagem poética, a reflexão desenvolvida em $O$ nascimento da tragédia trata de um domínio insondável da experiência, a ruptura da individuação experimentada no estado dionisíaco, e o modo como ele se exprime, em um primeiro momento, musicalmente e, em seguida, poeticamente, por meio da

16 Após comentar, no que diz respeito a Arquíloco, que "a investigação erudita descobriu que foi ele quem introduziu a canção popular na literatura", Nietzsche acrescenta: "na poesia da canção popular vemos, portanto, a linguagem empenhada ao máximo em imitar a música: daí começar com Arquíloco um novo universo da poesia, que contradiz o homérico em sua raiz mais profunda" (GT/ NT 5, KSA 1.49/trad. JG). Cf., também, REIBNITZ, op.cit., p.174-175.

Cad. Nietzsche, Guarulhos/Porto Seguro, v.38, n.2, p. 121-148, maio/agosto, 2017. | 143 
alegoria e do símbolo. Entre essas duas esferas forma-se, como vimos, uma lacuna, já que a linguagem poética não recobre inteiramente a música, não a traduz com precisão, mas simbolicamente, ligando por meio de imagens as duas esferas, que preservam de algum modo a irredutibilidade do movimento sonoro.

$\mathrm{Na}$ interpretação elaborada em $O$ nascimento da tragédia, encontram-se ressonâncias não tanto das questões especificamente analisadas no ensaio aqui abordado, mas sim de sua estrutura, já que precisamente essa estrutura, admiravelmente explicitada no conjunto formado pelos trechos extraídos por Nietzsche, nos remete a temas centrais do primeiro romantismo alemão, a partir dos quais Schlegel constrói sua interpretação da criação poética de Bürger. Entre esses temas, cabe destacar a filosofia romântica da linguagem e o papel central que a arte nela desempenha. Pode-se perceber, como observa Márcio Seligmann, três etapas ou níveis na reflexão sobre a linguagem elaborada pelos pensadores românticos ${ }^{17}$ : em primeiro lugar, uma origem divina, anterior à queda, na qual o homem compreende sem mediação a linguagem da natureza e não há distância entre os signos e os elementos designados. A queda, que se segue, na qual tem início a pluralidade das línguas, equivale ao caos e à não-compreensão, já que as palavras perdem o vínculo com aquilo que elas indicam, formando-se uma distância em relação às coisas. A teoria romântica compreende, enfim, um terceiro aspecto, o da "restituição da linguagem originária", a tarefa, que cabe ao filósofo e ao poeta, "de colher os cacos perdidos daquela antiga construção harmônica"18. Tal tarefa coincide com uma espécie de reencontro da linguagem originária, o que supõe, no entanto, um trabalho de recriação da linguagem por meio da restauração de seu caráter imagético. A esse respeito observa August Schlegel:

17 SELIGMANN-SILVA, M. Ler o Livro do Mundo. Walter Benjamin: romantismo e crítica poética. São Paulo: Iluminuras/FAPESP, 1999, p. 23-32.

$18 \mathrm{Ibid}$, p. 26.

144| Cad. Nietzsche, Guarulhos/Porto Seguro, v.38, n.2, p. 121-148, maio/agosto, 2017. 
A linguagem passa da pura expressão ao uso arbitrário com a finalidade de representação; quando, porém, o uso arbitrário torna-se seu caráter dominante, desaparece a conexão do signo com o designado e a linguagem passa a constituir apenas uma coleção de cifras lógicas, capaz de realizar as contas do entendimento. Para torná-la novamente poética, é preciso restabelecer seu caráter imagético, e isso porque o impróprio, o transposto, o trópico são considerados como essenciais à expressão poética (Lições, p. 83).

Se com o predomínio do uso arbitrário da linguagem, as palavras se distanciaram daquilo que elas indicam, tornando-se um instrumento, um simples meio de comunicação, a possibilidade de restituição significa que nelas sobrevive um âmbito irredutível, no qual ecoa aquela linguagem original perdida. A poesia, situada após a divisão, intervém, por assim dizer, para transpor a insuficiência da linguagem, o que se dá pela restauração de seu caráter imagético, pela qual ela imprime à palavra uma pluralidade de sentidos, abrindo-a a múltiplas interpretações. A perspectiva poética, segundo Schlegel, é aquela que vê nas coisas "um caráter figurado inesgotável" (Lições, p. 81), o que evidencia que a expressão indireta não é um mero aspecto da poesia, mas seu princípio constitutivo. Assim, se a concepção romântica é permeada por uma constante crítica à noção utilitário-comunicativa da linguagem, cabe à poesia retirá-la da esfera instrumental, liberá-la de ter de servir, constituindo o espaço no qual, como afirma Márcio Seligmann ${ }^{19}$, a linguagem se manifesta como poiesis, criação absoluta.

$\mathrm{Na}$ reflexão desenvolvida por Nietzsche em sua primeira obra, como vimos, ecoa uma série de temas - que se estende da intraduzibilidade do estado musical, passando pela análise dos limites da linguagem à afirmação da riqueza do modo figurativo de expressão - comum ao núcleo de pensadores que se reuniu, nos últimos cinco anos do século XVIII, em torno da revista Athenaeum e que é retomada por August Schlegel tanto na elaboração de suas Lições

19 Ibid, p. 32

Cad. Nietzsche, Guarulhos/Porto Seguro, v.38, n.2, p. 121-148, maio/agosto, 2017. | 145 
sobre belas letras e arte quanto de seu ensaio Bürger. É esse campo de questões, no qual a arte é entrelaçada à filosofia da linguagem, que, profundamente revisto, transformado à luz de novos autores, inserido em uma rede distinta de relações, permanece atuante no texto de Nietzsche e constitui, ao lado da reflexão sobre a arte dramática, um laço significativo que une $O$ nascimento da tragédia ao primeiro romantismo alemão.

\section{Referências bibliográficas}

BEHLER, E. Nietzsche und die Frühromantische Schule In: Nietzsche-Studien 7, 1978.

BEHLER, E. Sokrates und die Griechische Tragödie. Nietzsche und die Brüder Schlegel über den Ursprung der Moderne. In: Nietzsche-Studien 18, 1989.

BÜRGER, G. A. L. Tradução de Bernardo Taveira Junior. In: COLEN, E. ; DRUMOND, L. Das tempestades: a poesia alemã do Sturm und Drang. Edição bilíngue. Belo Horizonte: FALE/UFMG, 2010.

CAVALCANTI, A. H. Nietzsche e a leitura de Do Belo Musical de Eduard Hanslick. In: Cadernos Nietzsche São Paulo, n. 16, 2004, p. 53-84.

CAVALCANTI, A. H. Símbolo e Alegoria: a gênese da concepção de linguagem em Nietzsche. São Paulo: Annablume/Fapesp, Rio de Janeiro: DAAD, 2005.

CAVALCANTI, A. H. Nietzsche leitor de August Schlegel. In: PASCHOAL, E. ; FREZZATTI, W. (org) 120 anos de Para a Genealogia da Moral. Ijuí: Editora Ijuí, 2008, p. 47-68.

CRESCENZI, L. Nietzsche, August Wilhelm Schlegel und die Spuren Lessings. In: Nietzsche Studien 23,1993.

GUSDORF, G. Le savoir romantique. In: Le romantisme. Tome I. Paris: Payot, 2011.

HENRICHS, A. The last of the detractors: Friedrich Nietzsche's condemnation of Euripides. Greek, Roman and Byzantine Studies 27, 1986.

$146 \mid$ Cad. Nietzsche, Guarulhos/Porto Seguro, v.38, n.2, p. 121-148, maio/agosto, 2017. 
NIETZSCHE, F. Sämtliche Werke. Kritische Studienausgabe. Edição organizada por G. Colli e M. Montinari. München: Walter de Gruyter, 1980.

NIETZSCHE, F. Werke. Kritische Gesamtausgabe. Nachgelassene Aufzeichnungen (Herbst 1862 - Sommer 1864). Figl, J. e Hödl, H. G. (org), Berlin/New York: Walter de Gruyter, v. I/3, 2006.

NIETZSCHE, F. O nascimento da tragédia. Trad. J. Guinsburg. São Paulo: Cia das Letras, 1992.

NIETZSCHE, F. A visão dionisíaca de mundo e outros textos de juventude. Trad. Marcos Sinésio Fernandes e Maria Cristina de Souza. São Paulo: Martins Fontes, 2005.

REIBNITZ, B. Ein Kommentar zu Friedrich Nietzsche „Die Geburt der Tragödie aus dem Geist der Musik“, Stuttgart/Weimar: J. B. Metzler, 1992.

SCHLEGEL, A.W. Die Kunstlehre. Kritische Schriften. Lohner, E. (org,). v. 2, Stuttgart: W. Kohlhammer Verlag, 1963.

SCHLEGEL, A.W. Bürger In: Kritische Schriften. Staiger, E. (org). Zürich und Stuttgart: Artemis Verlag, 1962.

SELIGMANN-SILVA, M. Ler o Livro do Mundo. Walter Benjamin: romantismo e crítica poética. São Paulo: Iluminuras/FAPESP, 1999. 


\begin{abstract}
In 1863, in his last year of study at the famous Pforta school, Nietzsche read Lectures on Literature and Art and the essay Bürger by A. W. Schlegel, both on which he made notes. It was from such texts that he gained access to a detailed exposé on romantic theory regarding art and language, as well as an analysis on the work of the poet Gottfried August Bürger. His interest in the romantic aesthetics of August Schlegel would persist in the following years, continuing through the entire period in which he wrote The Birth of Tragedy. This article aims to examine Nietzsche's reception of Schlegel's works, notably the essay Bürger, as well as expound on important aspects of the dialogue he established with the early German romanticism.
\end{abstract}

Keywords: Nietzsche - A. W. Schlegel - Early German romanticism - language, poetry.

Artigo recebido para publicação em 04/02/2017. Artigo aceito para publicação em 28/04/2017. 